\title{
Reducing poverty and inequality through tax-benefit reform and the minimum wage: the $U K$ as a case-study
}

\author{
Anthony B. Atkinson ${ }^{1}$ - Chrysa Leventi ${ }^{2}$. \\ Brian Nolan $^{3}$ • Holly Sutherland ${ }^{2}$ - Iva Tasseva ${ }^{2}$
}

Published online: 6 December 2017

(C) The Author(s) 2017. This article is an open access publication

\begin{abstract}
Atkinson's book Inequality: What Can Be Done? (Harvard University Press, 2015) sets out a range of concrete proposals aimed at reducing income inequality, which cover a very broad span but include major changes to the income tax and social transfers system and the minimum wage. These are framed with specific reference to the UK but have much broader relevance in demonstrating how substantial the impact on inequality of such measures could be. This paper assesses the first-round effects of these tax, transfer and minimum wage reforms on income inequality and poverty based on a microsimulation approach using EUROMOD. The reforms involve a significantly more progressive income tax structure, a major increase in the minimum wage to the level which is estimated to represent the 'Living Wage', and alternative routes to reforming social transfers - either to strengthen the social insurance element or to restructure the entire system as a Participation Income (a variant of Basic/Citizen's Income). The results show how the first-round effects of either set of tax and transfer proposals would be to substantially reduce the extent of income inequality and relative income poverty and the paper draws out how the two approaches differ in their effects. The additional impact of raising the minimum wage to the Living Wage is modest, reflecting in particular the position of beneficiaries in the household income distribution and the offsetting effects on household income of the withdrawal of means-tested cash transfers.
\end{abstract}

Electronic supplementary material The online version of this article (https://doi.org/10.1007/s10888-017-9365-7) contains supplementary material, which is available to authorised users.

Holly Sutherland

hollys@essex.ac.uk

1 Institute for New Economic Thinking and Nuffield College, University of Oxford, Oxford, UK

2 Institute for Social and Economic Research, University of Essex, Colchester, UK

3 Institute for New Economic Thinking, Department of Social Policy and Intervention and Nuffield College, University of Oxford, Oxford, UK 
Keywords Income inequality · Poverty · Redistribution · Tax-benefit reform • Microsimulation

\section{Introduction}

Rising inequality in rich countries is now a very widely-shared concern, due to its economic, social and political consequences as well as for its own sake (see for example OECD 2015a, b, and Stiglitz 2012). Atkinson (2015) argues that increasing income inequality is not inevitable but can be reversed, and sets out a range of concrete proposals aimed at doing so. These cover a very broad span going well beyond traditional redistributive tools, but include substantial increases in direct redistribution via the income tax and social transfer systems as well as increasing the minimum wage. These tax/transfer and minimum wage reforms are the focus of this paper, which assesses their potential impact on income inequality, poverty, and work incentives, as well as which types of household would gain versus lose. The specific proposals are framed with reference to the UK, but analysis of their likely impact on inequality and poverty yields insights of much broader relevance. In particular, they speak to central choices about the design and progressivity of income tax and social insurance contributions on the one hand, and the role of means-tested versus social insurance-based versus universal cash transfer payments on the other.

The UK is a particularly pertinent case to analyse in this context, because social insurance-based provision has been eroded and the role of means-testing expanded dramatically over recent decades (whilst income tax rates have been sharply reduced as in many other OECD countries). About four-fifths of non-pensioner social security spending is now means-tested, compared with around a quarter in the late 1970s; as the Institute for Fiscal Studies put it, "the contributory principle plays an increasingly marginal role in the social security system, particularly for those of working age" (Hood and Oakley 2014). Atkinson (2015) argues this is the wrong approach, on the basis that means-testing suffers from the twin failures of the high marginal tax rates created as benefits are withdrawn, combined with unmet need as some of those who are entitled to the benefits do not take them up, for a variety of reasons including complexity and stigma. ${ }^{1}$ At the same time, income taxation could do more to counteract increasing inequality in the distribution of income from the market.

Atkinson presents two alternative strategies in response. Each involves increasing income tax progressively and increasing Child Benefit substantially for all families, irrespective of means, thereby enhancing redistributive impact and, via increasing universal payments, allowing reliance on means-testing to be reduced. These are then combined either with strengthening social insurance or, alternatively, with the implementation of a form of 'basic income'.

Strengthening social insurance would build on and reinforce existing structures, and reverse some of the expansion in means-testing that has been such a striking feature of the recent UK experience. However, social insurance may have difficulty coping with what are widely discussed as "new social risks" associated with low pay, insecure intermittent employment and family dissolution, seen in the UK debate and elsewhere as posing major challenges to the insurance-based model. Raising social insurance rates will impact only on those entitled to those benefits, whilst extending coverage may not have immediate effects if additional entitlements have to be built up by more contributors/contributions.

\footnotetext{
${ }^{1} \mathrm{~A}$ review of the main advantages and disadvantages of means-testing and universalism can be found in Gugushvili and Hirsch (2014).
} 
On the other hand, a basic income paid to everyone irrespective of means and living situation has been advocated from different ideological starting-points and is now being seriously debated in various countries. (See for example the seminal study by Van Parijs 1995, Standing 2014, and Van Parijs and Vanderborght 2017; for analysis and discussion in a UK context see Parker 1989, Torry 2013, 2016, Reed and Lansley 2016, Piachaud 2016, Martinelli 2017). This would impact more broadly than strengthening social insurance, and may offer some advantages with respect to new social risks in particular. However, broad coverage means it would either be more costly or less generous, whilst involving much more fundamental structural change. The relative merits of these alternatives for work incentives, compared with ever-more reliance on means-testing, also plays a central role in the debate.

This paper aims to contribute to understanding and debate through an in-depth analysis of the impact of pursuing these alternative strategies in a UK context, using a static microsimulation approach. This employs the tax-benefit model for the UK incorporated into the broader EUROMOD microsimulation model for the European Union, based on data for a representative sample of UK households. This allows us to examine the immediate impact of the reform packages on household incomes taking into account the complex interactions between the different elements of the packages, exploiting the capacity of the microsimulation model to capture the detailed parameters of the actual and proposed tax-benefit structures. (See Figari et al. 2015, for an overview of microsimulation and policy analysis, and for comparative exercises with similar goals for example Atkinson et al. 2002, Levy et al. 2013.) We investigate the effects on a range of inequality and poverty measures and look at how different types of household and different parts of the income distribution are affected, bringing out the channels through which the reform packages have their (differing) effects. We also analyse their impact on the financial incentives facing those in work, both with respect to working versus not working and to changing their hours of work. Whilst we do not seek to take behavioural responses directly into account in the simulations, these measures of how financial incentives would change help to highlight where such responses in terms of labour supply might be more or less substantial.

We then investigate how these tax/transfer reforms align with another of Atkinson's (2015) proposals, to raise the National Minimum Wage (NMW) to the level of the Living Wage. This has become particularly salient in a UK context given that the British government now intends to raise the NMW significantly for those aged 25 or above over a period of years; it is again also of much broader relevance given the very active debates in many countries about the role of minimum wages in addressing inequality in wages and household incomes as well as poverty. (Studies focused on the UK minimum wage include Dickens and Manning 2004a, b, Butcher et al. 2012, Stewart 2011, and Brewer and De Agostini 2015; Vaughan-Whitehead 2009, compares a range of country experiences with respect to the minimum wage, whilst the role of minimum wages as part of a broader anti-poverty strategy is discussed in Marx and Nolan 2014, 2015.) Here we look at the immediate impact that raising the UK minimum wage might have on inequality and poverty, on its own or combined with the implementation of the alternative tax/transfer reform proposals. Once again this is done via a static microsimulation approach with no change in employment or hours taken into account, which is an essential first step in a broader assessment of such a minimum wage increase and how it interacts with alternative tax/transfer reform strategies.

Our findings show that such major tax/transfer reforms could reduce income inequality and poverty substantially, with the immediate effects of raising the minimum wage being much more modest. The results bring out the complex interactions between taxes, benefits and earnings underpinning how such reforms would impact, and the nature of the choices faced if inequality is to be addressed by these key policy tools. 
The structure of the paper is as follows. Section 2 presents the reform scenarios. Section 3 describes the methodology and data used in the analysis. The distributional and incentive implications of the proposals are presented in Sections 4 and 5. Section 6 summarises the main conclusions of the research.

\section{Outline of the proposals}

The UK's social security system has long been taken as the archetype of the Beveridgean structure centrally founded in social insurance, though means-testing always played a larger role than Beveridge had envisaged, since the insurance-based elements did not achieve either the coverage or level of payment required to residualise it. However, insurance-based payments declined from about $70 \%$ of total social security expenditure in the 1960s and early/mid-1970s to $50 \%$ by the mid-1990s, being sharply cut back by the Thatcher government in particular. Insurance-based payments have been further eroded since then, so that around four-fifths of non-pensioner social security spending is now means-tested, whilst the focus of government policy is on bringing separate means-tested schemes for those of working age together into an integrated Universal Credit scheme. Child Benefit, which had for many years been a universal payment made with respect to all children, has more recently been withdrawn from higher-income families. The work incentives associated with the system and reforms have been a central focus for policy-makers and researchers (see for example Adam and Browne 2010, 2013, 2015), whilst non-take-up of means-tested benefits has also featured as a long-term concern in the UK (see for example Atkinson 1995, Hernandez et al. 2007, Hancock et al. 2004) as well as elsewhere (Bargain et al. 2012; Eurofound 2015).

Income tax rates have been sharply reduced over the last 40 years, as seen in many other OECD countries. The current structure has a basic rate of $20 \%$ and a higher rate of $40 \%$, with an additional rate of $45 \%$ affecting only about $1 \%$ of the highest income taxpayers.

The final element of the point of departure for the reform package to be investigated is the National Minimum Wage (NMW). Introduced in 1999, this sets a statutory minimum applying to hourly gross earnings across all sectors of the economy (though lower rates may be paid to younger/inexperienced workers) and has been uprated intermittently over time on the basis of the recommendations of the independent Low Pay Commission set up to advise the government with respect to the operation of the NMW. In 2014, the base year for our simulations, the NMW represented about $40 \%$ of the mean hourly wage and $48 \%$ of the median hourly wage for full-time employees. Around 5\% of all jobs, a total of 1.4 million, were then paid at the minimum wage according to the Low Pay Commission (2015).

Against this base, the elements of the reforms we investigate here comprise: (i) restructuring income tax rates and employee social insurance contributions; (ii) raising Child Benefit levels of payment; (iii) Either increasing levels of payment for adults relying on social insurance benefits (which we will refer to as the SI option), or (iv) introducing a Participation Income for adults combined with abolishing the income tax personal allowance and exemption limit for social insurance contributions (which we will refer to as the PI option); and (v) raising the NMW to the level of the Living Wage.

As is commonly done, the tax and transfer elements of the reform examined here are designed to be budget neutral - in other words, any additional expenditure has to be financed by additional revenue raised by measures that are fully specified and included in the analysis. In Atkinson (2015) a different approach was adopted, with the tax and transfer measures designed to generate a surplus of $£ 2.5$ billion in order to fund other proposals included in his broader set, notably a capital endowment, a job guarantee, and an increase in the level of 
overseas aid. Here the income tax and social insurance changes proposed by Atkinson are implemented, with the specific parameters of the transfer reforms then configured to produce budget neutrality (in the first instance, before any behavioural responses). The increase in the NMW also has implications for the Exchequer, but these are treated separately.

The main features of each element of the reforms we simulate are now described, with full details given in the Appendix. To bring out how they differ from the baseline, the Online Appendix A shows how the reforms affect an illustrative household in different circumstances.

\subsection{Personal income tax and social insurance contributions}

A central element in Atkinson's proposals is to move to a more progressive rate structure for the personal income tax, with an initial rate of $25 \%$, intermediate rates of 35-55\%, and a top rate of $65 \%$. That top rate is much higher than the $45 \%$ in place currently in the UK, but not high by historical standards. Atkinson (2015) emphasises that intermediate as well as top rates are key to the average tax paid by those on high incomes, that estimates of a revenuemaximising top tax rate are subject to very substantial error, and that perceived fairness as well as maximising revenue is important. Low levels of earned income (including selfemployment and pension income) are taxed at a discounted rate of only $20 \%$, and the upper limit for social insurance contributions is raised.

\subsection{Raising child benefit}

Atkinson (2015) sees a substantial universal Child Benefit as central to any programme to reduce inequality. The arguments against means-testing already outlined, together with concerns about generational and gender equity, motivate a payment for all children rather than a targeted one. Making the payment taxable is a way of reducing the benefit for higherincome parents. A substantial increase in Child Benefit, which would be paid for all children but with a larger payment for the first child in the family, is a core element in Atkinson's proposals. Following Atkinson's proposal, we set the Child Benefit rate for all but the first child at $18 \%$ of the median equivalised household net income. This corresponds to 0.3 (the modified OECD equivalence scale value for a child) of the relative poverty line, equal to $60 \%$ of the median equivalised household net income. This means raising current UK payment rates by a factor of four. As in the current system, a substantially higher rate is paid in respect of the first child and the rationale for setting the precise rate is explained below.

\subsection{Strengthening social insurance}

One route for reform of cash transfers for adults proposed by Atkinson entails renewing and reinvigorating the social insurance system - a "Back to Beveridge" approach, as it were. This is especially salient in a UK context where the coverage of social insurance for those of working age has shrunk and benefit rates been eroded markedly, but is also of relevance in many other rich countries. Whilst an important aspect of such an approach is getting back to a broader coverage, for the purpose of this simulation exercise we focus on the raising of payment rates. For insurance-based state pensions these rates are increased by one-quarter, whilst for the unemployed, currently paid less, the rate is raised by over half. Under this scenario the greatly increased Child Benefit would become taxable in the hands of the parent (in a couple, the person with the lower taxable income). The combination of 
increased income tax, Child Benefit, and social insurance rates is configured to be revenue neutral in the first instance (with the Child Benefit rate for the first child set to achieve this, given the other tax and transfer changes being simulated).

\subsection{Participation income}

Atkinson (2015) puts forward as an alternative to strengthening social insurance the introduction of a form of basic income. The idea of a universal payment replacing existing social transfers (and income tax concessions) is an old idea currently receiving renewed attention, but the Participation Income (PI) version advanced by Atkinson is for a partial payment that would complement rather than replace existing social transfers. Existing insurance-based social protection and pension schemes remain in place but where recipients are below the PI they are brought up to it, whilst the PI partially substitutes for means-tested schemes which remain in place but include the PI in their income tests. In Atkinson's formulation the PI would be paid to adults meeting a participation condition, for example caring for a child or an adult, seeking job training, doing voluntary work, doing paid work, etc., as well as those unable to participate due to ill-health or disability. Since this participation condition cannot be imposed in our simulation exercise due to lack of data, this is carried out on the basis that everyone is entitled. The level of PI we simulate is $£ 75$ per week or $£ 3,902$ per year which, like the SI alternative, is revenue-neutral when combined with the tax and Child Benefit reforms. ${ }^{2}$ In this scenario Child Benefit acts as the child equivalent of the adult PI and is not taxed. The existing income tax and social insurance contribution income thresholds below which no tax/contribution is payable are abolished so these are payable on all incomes other than the PI.

\subsection{The minimum wage}

We consider an increase in the NMW for those aged 21 or over from $£ 6.31$ to $£ 9.15$ if living in London or $£ 7.85$ for those living outside London, with similar proportionate increases for younger workers. These figures are based on the most widely-used estimates of the 'Living Wage' required to meet minimum needs in the UK. ${ }^{3}$ (In mid-2015 the UK government announced that it intended to raise the NMW substantially over a period of years, for those aged 25 and over only, and began that process in 2016; the 2014 baseline used here is before that increase.)

\section{Simulating the impact on inequality and poverty: methodology and data}

The initial impact of these reforms on income inequality and poverty is examined by combining household survey data and microsimulation techniques, taking a household level approach to analysing the redistributive as well as fiscal effects of the reforms. Using the tax-benefit model EUROMOD we simulate each of the tax/transfer reform scenarios separately and compare them in depth. We then look at the impact of increasing the NMW, on its own and combined with the alternative tax-transfer packages.

\footnotetext{
${ }^{2}$ Note that the headline simulation results in Atkinson (2015), had a lower increase in Child Benefit and higher adult payment with the PI option, whereas here we apply the same increase in Child Benefit in both SI and PI options to facilitate comparison between the two structures, aligning the total costs by reducing the adult PI rate.

${ }^{3}$ For more details, see: http://www.livingwage.org.uk/.
} 
EUROMOD uses survey micro data on gross market incomes, labour market status and other characteristics from a nationally representative household sample, the Family Resources Survey (FRS). It then applies the tax and benefit policy rules in place in a given year and calculates for each individual and their household in the data their liabilities for direct taxes and social insurance contributions and entitlements to cash benefits as well as the total household disposable (net) income. Due to lack of information in the survey data (e.g. previous working history and contributions), EUROMOD cannot calculate entitlements to certain benefits such as contributory pensions or disability benefits and so uses the information on receipts of these benefits that households have reported directly in the survey data. Furthermore, in the calculation of benefit entitlements EUROMOD takes into account the fact that some households may not claim the means-tested benefits they are legally entitled to (i.e. benefit non take-up). The adjustment is done by applying the take-up proportions published by the Department for Work and Pensions (2010) and HM Revenue and Customs (2010). ${ }^{4}$

One of the main advantages of EUROMOD (and microsimulation models in general; see for example Bourguignon and Spadaro 2006) is that it can calculate individual/household benefit entitlements and tax liabilities under hypothetical policy reforms. EUROMOD accounts for the interactions between policy rules and household circumstances as well as between the different policies which are vital for accurately estimating the first-order distributive and fiscal implications of policy reforms. The resulting levels of household disposable income after simulating the 2014/15 tax-benefit policies constitute our baseline scenario with which all reform scenarios are compared.

As already noted, we analyse the direct, first-order effects of the reforms and do not estimate any behavioural responses since these are highly complex to model and may be surrounded by large degrees of uncertainty, especially in the case of major structural reforms that may affect behaviour in several domains. Thus, we assume the same means-tested benefit non take-up rates in the baseline and in all reform scenarios, and the levels of employment and hours worked are held unchanged throughout. In-kind benefits and indirect taxes such as VAT and excise duties fall outside the scope of this analysis.

EUROMOD has been extensively validated both at household level (i.e. case-by-case validation) and aggregate level (i.e. against administrative statistics on benefit expenditures, recipients, tax payers etc.) and has been widely used in the economics and social policy literature. See Sutherland and Figari (2013) for an overview and De Agostini and Sutherland (2014) for a detailed description of the UK component as well as an explanation of why the baseline indicators are not exactly the same using simulated values as they are using FRS data.

The household survey data we make use of are drawn from the FRS for 2009/10 which has a sample comprising 25,200 households with 57,380 individuals. The data contain very rich information on individual and household characteristics and financial circumstances. ${ }^{5}$

To account for income growth between the data income reference year (2009/10) and the year of interest in our analysis (2014/15) we apply growth factors by income source. For example, we adjust employment income by the growth in average weekly earnings.

\footnotetext{
${ }^{4}$ For more information on the take-up probabilities used for each benefit and the non take-up modelling approach in EUROMOD, see De Agostini and Sutherland (2014).

${ }^{5}$ The FRS is also the main source of data for the Households Below Average Income (HBAI) annual reports produced by the UK Department for Work and Pensions providing detailed information on households' living conditions measured by income in the UK. http://webarchive.nationalarchives.gov.uk/20120930153352/ http://statistics.dwp.gov.uk/asd/frs/2009_10/frs_2009_10_report.pdf
} 
Disability benefits, contributory pensions and Council Tax that cannot be simulated with the information available in the FRS are also updated to their 2014/15 levels according to actual indexation practise during this period. No adjustments are made for changes in the labour market, household composition or demographic characteristics of the population over this period.

An important issue to be taken into account in using EUROMOD for the specific application we are engaged in here relates to the way earnings are captured in the FRS and the bias this may introduce into the number of employed seen to be below the National Minimum Wage. The FRS asks respondents their weekly earnings and weekly hours worked, but taking the ratio of these two may produce a biassed estimate of the worker's actual hourly wage (see, for example, Skinner et al. 2002). This can be seen by comparison with the Labour Force Survey that directly asks workers paid by the hour about their hourly pay. We therefore follow Brewer and De Agostini (2015) in imputing to all employees in the FRS an adjusted measure of their hourly wage rate, using a set of covariates common to both datasets. ${ }^{6}$ These adjusted earnings figures are used as the basis for calculating household net incomes in EUROMOD in the 2014 baseline and throughout our analysis. In then simulating the Minimum Wage reform, those with earnings in the baseline below the Living Wage for their age group, distinguishing those in/outside London, have their hourly earnings brought up to the relevant Living Wage.

The impact of the reforms on income inequality is assessed first in terms of a number of summary inequality measures, namely the Gini coefficient, the Atkinson measure (with its inequality aversion parameter set at 0.5 ), the mean log deviation, and the Theil index. Employing a variety of summary inequality measures provides a rounded picture since they incorporate different distributional weights and may thus give differing results. The impact on poverty is assessed in terms of the population proportions falling below a relative income threshold set at $60 \%$ of median household disposable income (adjusted for household size using the modified OECD equivalence scale), which is widely used in both a UK and EU context (in for example the official Households Below Average Income annual report and the EU's suite of Social Inclusion indicators). ${ }^{7}$ Poverty gap measures - reflecting the distance those in poverty on this measure are below the income threshold - are also employed to capture the impact on those who remain below the poverty threshold but still see some increase in their incomes. We calculate standard errors for the results based on the DASP package by Araar and Duclos (2007) in Stata, taking into account sampling variation.

The incidence of changes across deciles of the baseline income distribution allow us to see where the effects underlying these summary measures are to be found, and also show which parts of the reform packages make the most difference. The average change within each income decile group, as well as the overall budget neutral situation is further explored by examining the proportions gaining versus losing from each reform package.

Finally, the impact on work incentives is assessed in terms of the impact on poverty 'traps', where those in work see little or no financial return from working more hours or even compared with not working. This is captured by measuring the marginal effective tax

\footnotetext{
${ }^{6}$ This is done separately for first and second jobs, with predictors including age and age squared, marital status, number of dependent children by age, highest qualification, region of residence, part-time (only for main job), occupation, firm size and industry sector.

${ }^{7}$ Note that the poverty threshold as derived in the baseline is held fixed across the simulations even where median income changes, since otherwise the impact of the reforms on those in or around the poverty line may be obscured by their impact on the median. The same applies to the ranking of households by decile group.
} 
Table 1 Impact of alternative tax/benefit reforms on inequality

\begin{tabular}{|c|c|c|c|c|c|c|c|c|}
\hline & Gini & Change & $\begin{array}{l}\text { Atkinson } \\
\varepsilon=0.5\end{array}$ & Change & $\begin{array}{l}\text { MLD } \\
\alpha=0\end{array}$ & Change & $\begin{array}{l}\text { Theil } \\
\alpha=1\end{array}$ & Change \\
\hline Baseline & 31.9 & & 8.5 & & 17.9 & & 18.6 & \\
\hline $\mathrm{Tax}+\mathrm{CB}+\mathrm{SI}$ & 28.9 & $\begin{array}{l}-3.0 * * * \\
(0.08)\end{array}$ & 6.9 & $\begin{array}{l}-1.6^{* * * *} \\
(0.18)\end{array}$ & 14.3 & $\begin{array}{l}-3.7 * * * \\
(0.17)\end{array}$ & 14.7 & $\begin{array}{l}-3.9^{* * *} \\
(0.31)\end{array}$ \\
\hline $\mathrm{Tax}+\mathrm{CB}+\mathrm{PI}$ & 26.2 & $\begin{array}{l}-5.7 * * * \\
(0.10)\end{array}$ & 5.7 & $\begin{array}{l}-2.8^{* * * *} \\
(0.20)\end{array}$ & 11.5 & $\begin{array}{l}-6.4^{* * * *} \\
(0.22)\end{array}$ & 12.3 & $\begin{array}{l}-6.3^{* * *} \\
(0.33)\end{array}$ \\
\hline
\end{tabular}

Notes: The change is in ppts relative to the baseline. Significance levels indicated as *p $<0.1, * * p<0.05$, $* * * \mathrm{p}<0.01$. Standard errors in parenthesis

Source: Authors' calculations with EUROMOD and FRS

rate (METR) facing those with some earnings if their income increases, and the Participation Tax Rate (PTR) capturing the proportion of gross earnings lost in higher tax liabilities or lower social transfers if moving into work. Higher METRs or PTRs indicate weaker work incentives. (For more detail on these measures and their calculation, see the Online Appendix B.)

\section{The impact of the tax and transfers proposals}

The impact of the tax and transfer reforms on summary inequality measures is shown in Table 1. The Tax $+\mathrm{CB}+\mathrm{SI}$ reforms reduce the Gini coefficient from 31.9 to 28.9, a reduction of over $9 \%$. The Tax $+\mathrm{CB}+\mathrm{PI}$ option achieves double this reduction, lowering the Gini by $18 \%$ to 26.2 . The corresponding results with alternative summary inequality measures that assign more weight to the bottom reveal larger proportionate reductions, of about one-fifth in the case of the Tax $+\mathrm{CB}+\mathrm{SI}$ package and at least one-third in the case of the Tax $+\mathrm{CB}+\mathrm{PI}$ package. ${ }^{8}$

Focusing on poverty, Table 2 shows results first for all persons and then for children. We see that the percentage of persons in households below $60 \%$ of median equivalised disposable income is reduced by the $\mathrm{Tax}+\mathrm{CB}+\mathrm{SI}$ reforms from $15.2 \%$ to $12.2 \%$, a reduction of one-fifth. The (unweighted) poverty gap expressed as a proportion of total disposable income is reduced by $24 \%$, so as well as bringing households up to the threshold the reform reduces the poverty gap for some others left below it. The Tax $+\mathrm{CB}+\mathrm{PI}$ reform has a considerably larger impact, bringing the poverty headcount down by $38 \%$ and the poverty gap by $58 \%$. This reform directs resources towards those below the threshold not in receipt of insurance-based payments, who cannot benefit from those being increased. They will benefit in particular if they are in receipt of only modest amounts of means-tested payments or are not taking up their means-tested entitlements. The impacts on child poverty are considerably greater for both reforms, with the $\mathrm{Tax}+\mathrm{CB}+\mathrm{PI}$ package in particular reducing the child poverty gap by a striking four-fifths. ${ }^{9}$

\footnotetext{
${ }^{8}$ The Lorenz curves for the baseline and the two reform scenarios lie inside each other: Tax $+\mathrm{CB}+\mathrm{PI}$ inside $\mathrm{Tax}+\mathrm{CB}+\mathrm{SI}$ and both inside the baseline.

${ }^{9}$ It is worth noting that using the same resources to pay all children a common rate of Child Benefit has less impact than the approach here which devotes more to the first child in the family.
} 
Table 2 Impact of alternative tax/benefit reforms on poverty

\begin{tabular}{lllll}
\hline & $\begin{array}{l}\text { Poverty } \\
\text { headcount }(\%)\end{array}$ & Change in ppts & $\begin{array}{l}\text { Poverty } \\
\text { gap (\%) }\end{array}$ & Change in ppts \\
\hline $\begin{array}{llll}\text { All } \\
\text { Baseline }\end{array}$ & 15.2 & & 4.5 & \\
Tax+CB+SI & 12.2 & $-3.0^{* * *}$ & 3.4 & $-1.1^{* * *}$ \\
& & $(0.14)$ & & $(0.04)$ \\
Tax+CB+PI & 9.4 & $-5.8^{* * *}$ & 1.9 & $-2.6^{* * *}$ \\
& & $(0.22)$ & & $(0.08)$ \\
Children & 16.1 & & 4.3 & \\
Baseline & 11.5 & & 2.3 & $-2.0^{* * *}$ \\
Tax+CB+SI & & $-4.6^{* * *}$ & & $(0.09)$ \\
Tax+CB+PI & 6.6 & $(0.30)$ & 0.9 & $-3.4^{* * *}$ \\
& & $-9.5^{* * *}$ & & $(0.15)$ \\
\hline
\end{tabular}

Notes: Significance levels indicated as $* \mathrm{p}<0.1,{ }^{*} \mathrm{p}<0.05, * * * \mathrm{p}<0.01$. Standard errors in parenthesis Source: Authors' calculations with EUROMOD and FRS

As Fig. 1 shows the incidence across the baseline income distribution of both reform options results in increases in income for each of decile groups 1-7, no change for the 8th decile group, and a decline for the top two decile groups. The increase in the level of social insurance benefits $(\mathrm{Tax}+\mathrm{CB}+\mathrm{SI})$ and the introduction of the $\mathrm{PI}(\mathrm{Tax}+\mathrm{CB}+\mathrm{PI})$ as well as the increase in the Child Benefit amounts (both packages) are (partly) offset by i) the increase in income tax liabilities and social insurance contributions and ii) the withdrawal of means-tested benefits. Both the increases towards the bottom and the reductions at the top are larger with the PI than the SI option. This is particularly the case for the poorest income decile, for which the estimated increase in its disposable income share is $50 \%$ with the PI option compared to $16 \%$ with the SI option and is in spite of the fact that increases in taxes affect the bottom much more under the Tax $+\mathrm{CB}+\mathrm{PI}$ option (because non-PI income is taxed from the first pound).

A very substantial proportion of households are affected by each of the reform packages. With the SI option, about $54 \%$ of all households would gain whilst $28 \%$ would lose. Under the PI option the proportions are somewhat larger: $58 \%$ of households with some gain and $36 \%$ with some loss. Focussing on those with gains or losses of at least $5 \%$ of their baseline income (see Fig. 2) shows a larger discrepancy between the two schemes. With the SI option $34 \%$ would see a gain and $10 \%$ would lose that much. With the PI option $42 \%$ of all households would see a gain of $5 \%$ or more and $21 \%$ a loss of that scale. So the $\mathrm{Tax}+\mathrm{CB}+\mathrm{PI}$ package, in bringing about a substantially greater reduction in income inequality and poverty, is having substantial effects in both directions on considerably more households. ${ }^{10}$

\footnotetext{
${ }^{10}$ Many of the same households are affected by the alternative packages in terms of substantial gains and losses. Almost two-thirds of those who gain at least $5 \%$ with the Tax $+\mathrm{CB}+\mathrm{SI}$ package also do so with the Tax + CB + PI reform, whilst most of those who lose $5 \%$ or more with the SI package also do so with the PI package.
} 


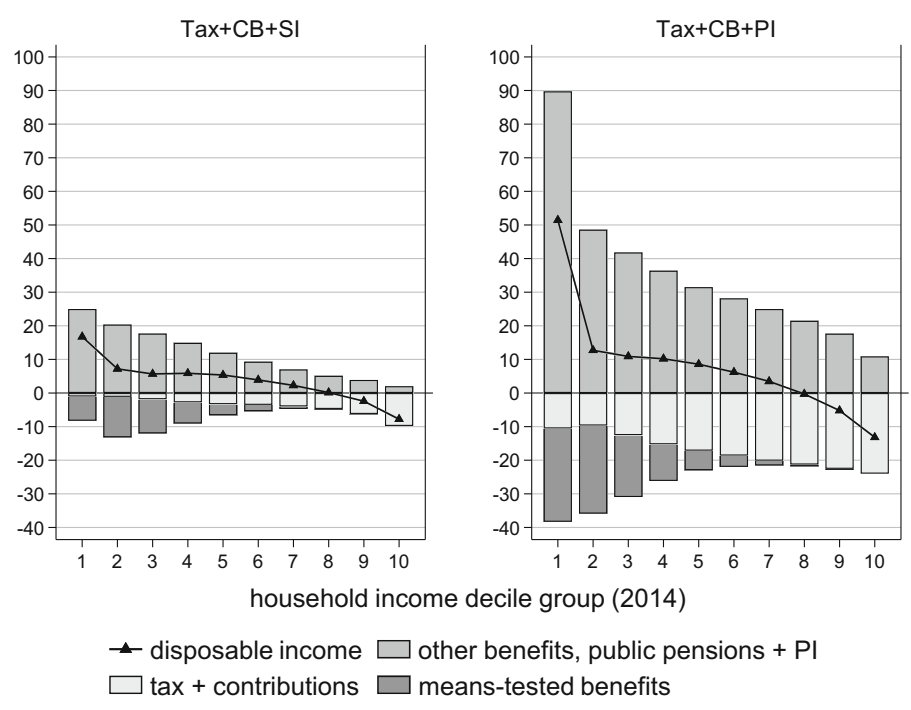

Note: Ranking of individuals by household disposable income, equivalised using the modified OECD scale, using the 2014 baseline.

Source: Authors' calculations with EUROMOD and FRS.

Fig. 1 Percentage change in household income by decile group

Figure 2 compares the two packages in terms of the percentage in each decile group seeing an income gain or loss of $5 \%$ or more. Focusing first on gains, we see that with the Tax $+\mathrm{CB}+\mathrm{SI}$ option about half the households in the bottom six decile groups see such gains. The proportion of such gainers declines rapidly after the seventh decile. With the Tax $+\mathrm{CB}+\mathrm{PI}$ option the proportion with a substantial gain is larger across the bottom half of the distribution, notably for the first income decile.

Focusing on those with losses of $5 \%$ or more, Fig. 2 shows that with the Tax $+\mathrm{CB}+\mathrm{SI}$ option the percentage losing substantially is very low up to the 7 th decile. It is still only $20 \%$ for the 9 th decile, but then rises sharply to $65 \%$ in the top decile. The percentage experiencing substantial losses is higher with the Tax $+\mathrm{CB}+\mathrm{PI}$ package across the entire distribution. This primarily reflects the elimination of the thresholds below which income tax and social insurance contributions are not payable, so these are levied on all income. This results in a loss even at lower incomes if the gain from the PI is also offset by reductions in means-tested entitlements.

It is also important to assess how the pattern of substantial gainers and losers varies across the income distribution by characteristics such as age and household composition and circumstances such as the number of household members with earnings. In interpreting these patterns one must be aware that the underlying number of households to which some of these percentages apply is sometimes small-because for example there are not many 2-earner households towards the bottom of the distribution. The distribution of household types by income decile and the percentages of gainers and losers in each of the groups are presented in the Online Appendix C. 


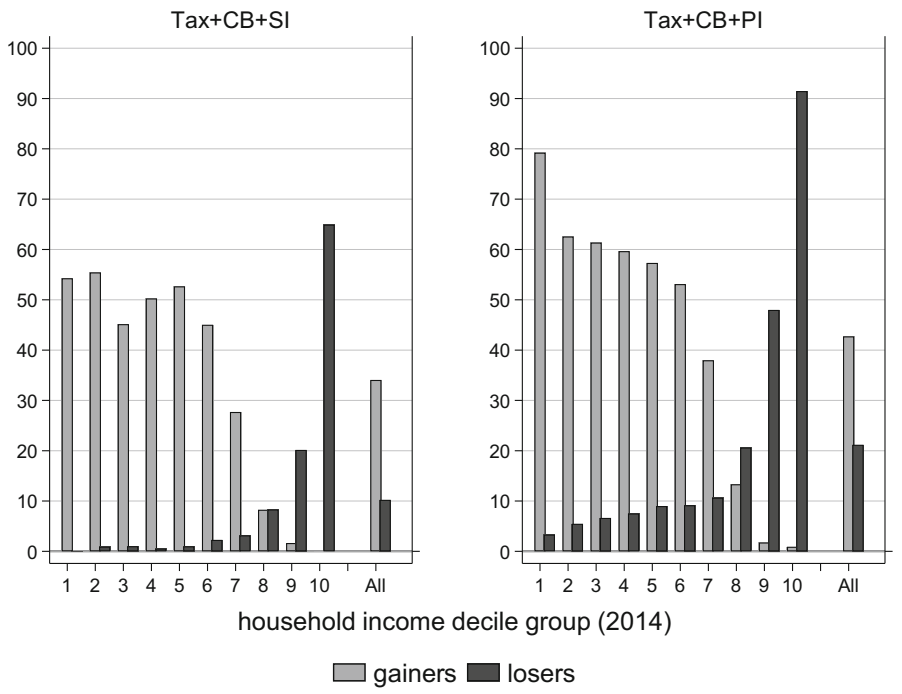

Source: Authors' calculations with EUROMOD and FRS.

Fig. 2 Percentage of households gaining or losing 5\% or more from alternative tax/benefit reforms by income decile

The most striking difference between the two reform packages is with respect to households with older people, where a majority gain with the Tax $+\mathrm{CB}+\mathrm{SI}$ package compared with only $10 \%$ gaining with the Tax $+\mathrm{CB}+\mathrm{PI}$ package. This reflects the fact that the insurance-based state pension has been increased by $25 \%$ in the Tax $+\mathrm{CB}+\mathrm{SI}$ package, whereas in the $\mathrm{Tax}+\mathrm{CB}+\mathrm{PI}$ package those receiving a full insurance pension see no gain. Our results also suggest that very few elderly households lose substantially with the $\mathrm{Tax}+\mathrm{CB}+\mathrm{SI}$ package except at the top of the distribution. The Tax $+\mathrm{CB}+\mathrm{PI}$ reform on the other hand produces substantial losses for those households outside the bottom two decilesprincipally because all their other income is liable to tax from the first pound. By contrast, a substantial proportion of households with children gain with each of the packages and very few lose, except at the top, reflecting the substantial increases in Child Benefit, which is common to both schemes. There are, nevertheless, considerably more gainers across the bottom two-thirds of the distribution with the PI option, since more households with children also gain from the PI itself.

Reducing the role of means-testing is a central aim of the reforms, for the reasons set out in the introduction. Just over 9 million households were in receipt of payments from the means-tested income support schemes in the baseline being used for our simulations (2014-15). The Tax $+\mathrm{CB}+$ SI reform would reduce that by almost $12 \%$. It would also reduce expenditure on means-tested support schemes by $25 \%$. The Tax $+\mathrm{CB}+\mathrm{PI}$ reform would reduce the number in receipt of payments from the means-tested income support schemes by $22 \%$, and total spending on these benefits goes down by $53 \%$-about twice the effect of the SI package.

This has clear implications for the impact of the reforms on work incentives and particularly on the marginal effective tax rate (METR) facing those who are earning, to which we now turn. The mean METR (i.e. the proportion of a small increase in earnings that would be lost in either higher tax payments or lower means-tested benefit entitlements) 
across these persons in the baseline is $36 \%$, and in the Tax $+\mathrm{CB}+\mathrm{SI}$ reform simulation this average increases to $41 \%$. With the Tax $+\mathrm{CB}+\mathrm{PI}$ package the overall average METR rises considerably more, to $48 \%$. Since one of the motivations of the SI and PI is to reduce high METRs due to means-testing, it is informative to identify the contributions of the different components of household income to these effects on the average METR. With the $\mathrm{Tax}+\mathrm{CB}+\mathrm{SI}$ package, the changes to the income tax system add 5.8 percentage points to the average METR and the social insurance contributions add 0.5 , with the contribution of means-tested benefit withdrawal falling by over 2 percentage points, together producing the overall increase of over 4 percentage points. The corresponding figures for the Tax $+\mathrm{CB}+\mathrm{PI}$ package are that the income tax changes-now including the abolition of the personal allowance - add a full 14 points, the changes in social insurance contributions add another 1.4 points, whilst the contribution of means-tested benefit withdrawal falls by almost 4 percentage points-producing the overall increase of 12 points.

Figure 3 shows the impact on mean METRs by income decile group, in other words averaged over the individuals who are earning and in households in that part of the distribution. ${ }^{11}$ We see that the rise in the overall average METR with the Tax+CB+SI package is driven by increases for earners in the top half of the household income distribution, with little change for the bottom decile group and marked reductions for the third and fourth deciles. The increases in METRs in the top half reflect the impact of the increases in income tax rates and raising the earnings ceiling for social insurance contributions purposes. The income tax increases have less impact in the bottom half whilst employee social insurance contributions are unchanged there, and means-tested benefit withdrawal plays a reduced role in decile groups $2-5$ in particular as the increase in social insurance-based transfers makes them less important.

With the Tax $+\mathrm{CB}+\mathrm{PI}$ package, on the other hand, Fig. 3 shows that the average METR for the bottom decile group increases substantially, and mean METRs are also considerably higher from the fifth to the tenth decile group. This reflects the fact that, on the tax side, as well as higher income tax rates the personal tax allowance is abolished and employee social insurance contributions are also levied from the first pound. Thus, as the figure shows, these two components work to very substantially increase mean METRs across the entire distribution. A substantial reduction in the extent of withdrawal of means-tested transfers largely offsets this in deciles $2-4$, but is not sufficient to do so at the bottom and is much less significant in the top half of the distribution.

Although the PI itself is not liable to tax, the fact that under the Tax $+\mathrm{CB}+\mathrm{PI}$ package both income tax and social insurance contributions are levied on all additional income is thus central to its impact on METRs. In addition, the PI replaces some but not all the means-tested benefits received by many of the households receiving those transfers, so they continue to face high withdrawal rates as their earnings increase marginally. However, they would need less additional market income to escape from means-testing altogether than under the baseline. This is an important feature of what is in effect a partial basic income that is not captured by these marginal calculations.

As well as the financial incentive facing those in work to increase their hours or find a better-paying job, their incentive to remain in work is also of considerable importance. To capture the impact of the alternative reform packages on this aspect we calculate the Participation Tax Rate (PTR), which captures the proportion of gross earnings that is not

\footnotetext{
${ }^{11}$ As the Online Appendix $\mathrm{C}$ brings out, this means averaging over varying numbers of earners by decile, since there are far more earners in the middle and upper income ranges than towards the bottom.
} 


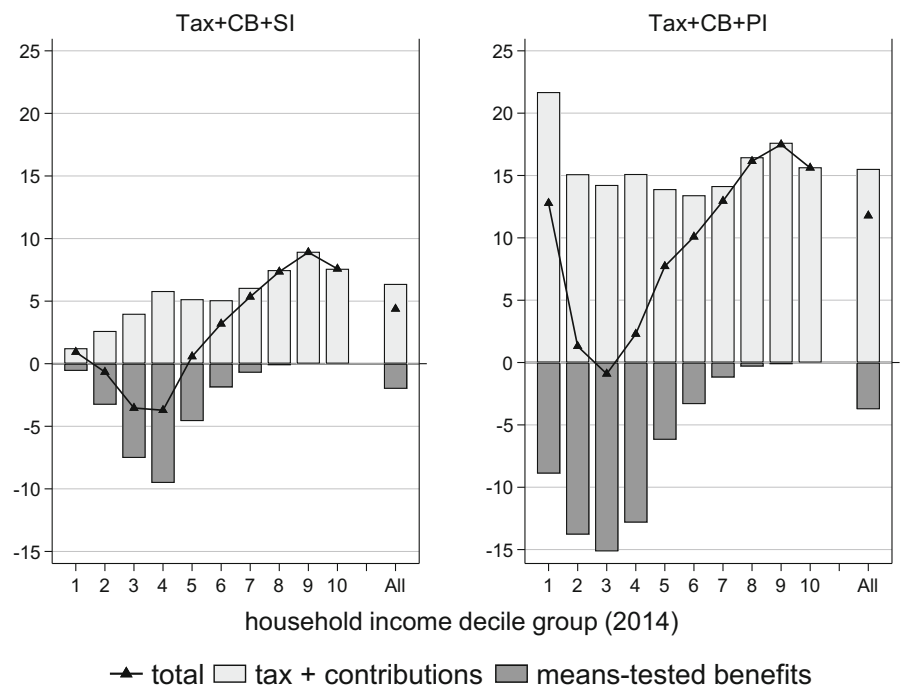

Source: Authors' calculations with EUROMOD and FRS.

Fig. 3 Percentage point change in mean METR from alternative tax/benefit reforms by income decile

reflected in an increase in the person's net income because it is lost in either higher tax liabilities or lower social transfers. ${ }^{12}$ The mean PTR in the baseline is $50.6 \%$, and ranges from over $60 \%$ towards the bottom, to $50 \%$ around the middle, and $40 \%$ towards the top of the income distribution; it is primarily driven by the social insurance benefits, and to a lesser extent means-tested payments, that those in work would receive if unemployed. With the Tax $+\mathrm{CB}+\mathrm{SI}$ package the mean PTR across earners rises to $62.7 \%$, with an increase of about this order seen across most of the income distribution (though greater for the bottom decile). This reflects the fact that insurance-based benefits, to which many of those in work would be entitled if they became unemployed, have been increased substantially. With the Tax $+\mathrm{CB}+\mathrm{PI}$ option, on the other hand, the mean PTR falls to $45.4 \%$. This fall is most pronounced towards the bottom of the income distribution, but average PTRs decline for the bottom $60-70 \%$. This reflects the fact that an individual in employment will still receive the PI amount, and only for the top third of the income distribution is this outweighed by the effect of the higher tax rates.

It is worth noting that both SI and PI strategies rely on entitlements defined at the level of the individual, whereas means-testing is (in the UK) applied to benefit units (essentially the nuclear family). This makes each of the reform strategies seem badly targeted and expensive when compared with the baseline family means-tested system and using indicators based on household income. However, there are positive features of individual-based entitlements that relate to independence and autonomy (Bennett and Sutherland 2011) as well as work incentives for second earners in couples.

\footnotetext{
${ }^{12}$ We estimate the PTRs on the sample of in-work individuals only as it does not require us to make strong assumptions about the wages of individuals who are currently out of work. Assuming that out-of-work individuals face higher PTRs, our estimates provide a lower bound. Nevertheless, we are primarily interested in the change rather than the level of PTRs and thus, we expect our conclusions to hold for the sample of out-of-work individuals too.
} 


\section{Raising the minimum wage to the living wage}

We now turn to the final element of the reforms to be analysed, which is a substantial increase in the minimum wage. As outlined earlier, the proposal to be examined is an increase the NMW up to the level of the Living Wage, from $£ 6.31$ to $£ 7.85$ per hour for those for those aged 21 and over living outside London and $£ 9.15$ if living in London, with similar increases for younger persons. Employment and hours worked are held unchanged in the simulations. With everyone in the (adjusted) sample with hourly earnings below the Living Wage brought up to that wage, $27 \%$ of all individual earners are affected. ${ }^{13}$

Our estimates suggest that almost $22 \%$ of households would see some income gain, and about one-third of those would see their disposable income increase by $5 \%$ or more. We look at the impact this has on inequality and poverty relative to the baseline, and also if it is combined with the alternative tax/transfer reform packages examined in the previous section. Detailed results for all indicators can be found in the Online Appendix D.

Raising the NMW to the Living Wage (LW) reduces the Gini coefficient only marginally, from 31.9 to 31.7 . The impact of the alternative tax/transfer packages on summary inequality measures is also marginally greater when they are combined with the increase in the Minimum Wage. This reform reduces the baseline poverty headcount by 0.4 percentage points and adds about that much to the poverty-reducing effect of each of the tax/transfer reform packages.

The limited impact of such a substantial increase in the Minimum Wage on income inequality and poverty reflects two key features of low pay and the tax/transfer system: low paid employees are widely spread across the household income distribution rather than concentrated towards the bottom, and for a substantial number of those affected some of the gain from the higher wage is clawed back by withdrawal of means-tested benefits. This is consistent with recent and earlier studies for the UK (Brewer and De Agostini 2015; D'Arcy et al. 2015a) and indeed with similar studies focused on the minimum wage in other countries (Marx and Nolan 2014). The reduction in poverty rates is even lower for women and children than the average impact, and the same is true of the effects on their poverty gaps. This reflects the fact that whilst women earners are more likely to be in low pay than men, male low earners are more likely to be in households below the income poverty threshold, and many are in single-person households.

Turning to the impact on work incentives, the simulation results show the increase in the Minimum Wage producing a small increase in the average Marginal Effective Tax Rate, from 36.1 to $36.4 \%$. Looking across the household income distribution, modest increases are seen in the average METR for the first, third and fourth deciles, with a marginal decline for the second decile. This reflects the varying balance between declines in METRs arising from reduced means-tested benefits versus increases associated with income tax and NI contributions. The overall number of households receiving means-tested benefits is reduced by about $1.3 \%$ of the number in receipt of such transfers in the baseline, and expenditure on those benefits is reduced by $1.5 \%$. Whilst not insignificant, this is very much less than the impact of the alternative tax/transfer reforms discussed above

\footnotetext{
${ }^{13}$ This is considerably higher than estimates of numbers to be directly affected by the increase in the NMW actually being implemented by the British government, produced for example by the Office for Budgetary Responsibility and the Resolution Foundation (D'Arcy et al. 2015a, b). This is mostly because the increase being simulated here is considerably greater than that being implemented, and unlike it applies to those aged under 25 .
} 
on the numbers relying on means-tested benefits, reflecting the fact that, as already highlighted, many of those who benefit from increases in the Minimum Wage are in households around the middle of the household income distribution. As might be expected, combining the Minimum Wage with the alternative tax/transfer reforms has only small additional effects on the numbers taken out of means-testing and negligible additional effects on work incentives.

Finally, raising the Minimum Wage with no changes in employment or hours worked would also be expected to have a significant positive impact on the government's finances via the extra income tax and social insurance contributions employees would pay on the additional earnings, as well as lower expenditure on social transfers. The simulation results suggest that, compared with the baseline, the extra revenue generated from income tax would be $£ 1.6 \mathrm{bn}$. and employee social insurance contributions would go up by $£ 1.1 \mathrm{bn}$. (Earned income goes up by a total of $£ 10.1 \mathrm{bn}$. in the Living Wage simulation, so households 'retain' over two-thirds of that total). With spending on in-work benefits also falling by $£ 1$ bn., the net gain for the Exchequer from lower spending and increased revenue would be of the order of $£ 3.7 \mathrm{bn}$.

However, increasing the Minimum Wage would also have other effects not captured here, such as potentially reducing company profits, which could impact negatively on other taxes. It would also have a direct impact on pay costs for the exchequer in bringing public sector employees up to the minimum, as well as indirect effects through the increased costs of services purchased from the private sector, including ones previously provided by public employees but now 'contracted out'. An overall assessment of the likely effects on the government finances is thus complex, and would also need to incorporate judgements about the extent to which the numbers in work and hours worked would be affected.

\section{Conclusions and implications}

This paper has analysed the first-order impact of tax and transfer reforms along the lines put forward by Atkinson (2015) to address rising income inequality, which entail increasing income tax in a progressive fashion, substantially raising universal Child Benefit, either strengthening social insurance or implementing a 'participation income' variant of basic income, and substantially increasing the Minimum Wage. The static microsimulation approach used the tax-benefit model for the UK in EUROMOD, based on data for a representative sample of UK households. Whilst the analysis relates to the UK the results are of much broader relevance, in particular informing debates about how to avoid the increasing reliance on means-testing which is seen in many countries but argued by Atkinson (2015) to be the wrong approach.

Our estimates show that each of the tax and transfer reform packages has a substantial impact on summary measures of inequality and poverty. Importantly, when one uses summary measures that are more sensitive than the Gini or the poverty headcount to the tails of the distribution, the impacts of the tax/transfer reforms are considerably larger. The $\mathrm{Tax}+\mathrm{CB}+$ SI package reduces the Atkinson and Theil inequality measures by one-fifth and the poverty gap by one-quarter; with the Tax $+\mathrm{CB}+\mathrm{PI}$ package these reductions are as much as one-third and three-fifths respectively. This bears out the claim that enhanced direct redistribution can be a major element in a broader strategy aimed at tackling inequality.

For the same overall cost, the Tax $+\mathrm{CB}+\mathrm{PI}$ package produces a larger immediate impact on both inequality and poverty because it directs resources towards low-income households not in receipt of the insurance-based payments that are the focus of the Tax $+\mathrm{CB}+\mathrm{SI}$ package. In 
achieving this greater impact the PI-focused package affects considerably more households, both positively and negatively: $43 \%$ of all households see a substantial gain and $21 \%$ a substantial loss, compared to $34 \%$ and $10 \%$ respectively with the SI-focused alternative.

As far as incentives to work are concerned, the effects are complex. The average marginal effective tax rate on earners rises considerably with the Tax $+\mathrm{CB}+\mathrm{SI}$ reform but by considerably more with the Tax $+\mathrm{CB}+\mathrm{PI}$ package, reflecting the increase in tax rates (which now apply on all income other than the PI itself). The mean participation tax rate rises sharply with the Tax $+\mathrm{CB}+\mathrm{SI}$ option, since the benefits that would be lost on taking up employment are higher, but falls with the Tax $+\mathrm{CB}+\mathrm{PI}$ package since the $\mathrm{PI}$ is received both in and out of work. The Tax $+\mathrm{CB}+\mathrm{SI}$ reform reduces the numbers in receipt of any means-tested payment, with expenditure on those schemes down by one-quarter as higher social insurance benefits float recipients off means-tested payments. The Tax $+\mathrm{CB}+\mathrm{PI}$ reform would reduce total spending on means-tested benefits by over one-half, because the PI replaces a significant proportion of means-tested support. Furthermore, whilst a substantial number of households do not benefit in net income terms because they simply receive PI instead of some of their means-tested payments, it is an important feature of such a partial basic income - not captured by marginal effective tax rates - that they then need much less market income to escape from means-testing altogether.

Finally, we examined the immediate impact of a substantial increase in the Minimum Wage, on its own or together with either of the tax/transfer reform packages. Whilst affecting a substantial proportion of earners, such an increase has only a very modest impact in reducing inequality or poverty. This reflects the fact that low paid employees are widely spread across the household income distribution rather than concentrated towards the bottom, and for a substantial number of those affected much of the gain from the higher wage would be clawed back by withdrawal of means-tested benefits. The inclusion of the Minimum Wage increase makes little difference to the impact of the alternative tax/transfer packages on the average METR across earners described in the previous section. Increasing the Minimum Wage does add modestly to the numbers lifted out of reliance on means-tested benefits with each package.

The impacts described here, across the various reforms, are static, first-round effects and an overall assessment would need to incorporate judgements about the extent and nature of behavioural responses. The measures of the effects on financial incentives we have reported are helpful in that regard with respect to the response of households; employer responses are of course also important, notably the potential dynamic effects of a higher minimum wage on investment in training and upskilling workers to enhance productivity.

These findings bring out the complexities involved in teasing out the potential distributional impacts of major (rather than marginal) reforms to the tax-benefit system, but also the value of in-depth microsimulation in seeking to do so. From a strategic perspective, the lessons are of relevance well beyond the UK. They show that the traditional levers of direct redistribution, though by no means the only tools available to tackle inequality, offer considerable scope to do so They also highlight the difficulties involved in seeking to move away from means-testing once it comes to play a dominant role. However, the results presented here suggest that this is challenging but possible, and that either strengthening social insurance or introducing a participation income offer feasible routes to doing so. The positive features of these reform strategies include the impact of individual-based entitlements on personal independence and autonomy that may be masked by focusing purely on household income. Combined with substantial universal child-focused income support and the reinforcement of progressive income taxation, they are a key part of 'what can be done' to reduce inequality. 
Acknowledgements Tony Atkinson sadly passed away on January 1st, 2017, as we were in the final stages of completing this paper. It fully reflects the discussions we had and our joint views. We are grateful to the journal editor and an anonymous reviewer for their constructive recommendations. We are also grateful to Paola De Agostini, Mike Brewer and Xavier Jara for their expert advice and assistance. We received helpful comments on earlier draughts at the 2016 London conference of the Association for Public Policy Analysis and Management (APPAM), the 2016 EUROMOD 20th Anniversary Conference at the University of Essex, and seminars at the University of Oxford Department of Social Policy and Intervention and the Institute for New Economic Thinking. We use EUROMOD version G2.11. Family Resources Survey data are made available by the Department of Work and Pensions via the UK Data Service. The authors alone are responsible for the analysis, interpretation and any errors that remain.

Open Access This article is distributed under the terms of the Creative Commons Attribution 4.0 International License (http://creativecommons.org/licenses/by/4.0/), which permits unrestricted use, distribution, and reproduction in any medium, provided you give appropriate credit to the original author(s) and the source, provide a link to the Creative Commons license, and indicate if changes were made.

\section{Appendix: Policy changes in detail}

\section{Changes common to both reform packages}

\section{Personal income tax and social insurance contributions}

Table 3 Income tax schedule

\begin{tabular}{lllll}
\hline $\begin{array}{l}2014 \text { baseline system } \\
\text { Rate }\end{array}$ & $\begin{array}{l}\text { Upper threshold of taxable } \\
\text { income (£/year) }\end{array}$ & $\begin{array}{l}\text { Reforms } \\
\text { With SI }\end{array}$ & With PI & $\begin{array}{l}\text { Upper threshold of taxable } \\
\text { income (£/year) }\end{array}$ \\
\hline $20 \%$ & 31,866 & $25 \%$ & $30 \%$ & 25,000 \\
$40 \%$ & 150,000 & $35 \%$ & $40 \%$ & 45,000 \\
$45 \%$ & n/a & $45 \%$ & $50 \%$ & 90,000 \\
& & $55 \%$ & $60 \%$ & 190,000 \\
& & $65 \%$ & $65 \%$ & n/a \\
\hline
\end{tabular}

Note that the thresholds apply to income after the deduction of the personal allowance. The level of this allowance varies across the baseline and the two reform scenarios. Note also that all rates but the top one are higher by 5 percentage points when combined with the Participation Income (PI) scheme than when combined with Social Insurance (SI). In addition, both reforms include an earned income discount for low income taxpayers such that a maximum of $20 \%$ of earned income (employment and self-employment earnings plus pensions) is deducted from the tax base. For annual earned income over $£ 23,333$ the discount is reduced at a rate of $40 \%$ up to taxable incomes of $£ 35,000$, when it is exhausted.

\section{Other income tax changes}

In the 2014 baseline system the personal allowance is withdrawn at high income. In the reforms this feature is removed. Furthermore, the married couples allowance and transfer between spouses of a part of un-used personal allowances are abolished.

\section{Social insurance contributions}

The upper limits for payment of full rates of contributions for employees and selfemployed are increased by $31 \%$ to $£ 55,000$ per year. 


\section{Child Benefit}

Table 4 Rates of payment $£ /$ week

\begin{tabular}{llr}
\hline & 2014 baseline system & Reform \\
\hline First child & 20.50 & 89.15 \\
Second and subsequent children & 13.55 & 52.50 \\
\hline
\end{tabular}

Changes to Child Benefit rates are shown in Table 4. The current withdrawal of Child Benefit at higher incomes is abolished.

So that the child benefit increases result in reductions in means-tested benefit entitlements the premia related to children in the benefits that do not include child benefit in their income test (Housing Benefit, Child Tax Credit, Council Tax Benefit) are reduced by the amount of the increase (or to zero if the increase exceeds them).

\section{Other changes}

The cap on the total amount of benefits that may be received is abolished.

\section{Strengthening Social Insurance}

As well as the changes listed in the first section, the following changes are made:

\section{Social insurance benefits}

The basic State Pension, Bereavement Allowance and contributory Employment and Support Allowance (ESA) are increased by $25 \%$.

Contributory Jobseeker's Allowance (JSA - unemployment insurance benefit), which starts lower is increased by $56 \%$.

\section{Income tax changes}

The personal tax allowance is reduced from $£ 10,000$ to $£ 8,000$ per year. Age additions are retained at their absolute value ( $£ 500$ per year for people aged between the state pension age and 74 and $£ 660$ per year for people aged over 75$)$.

\section{Other changes}

Child benefit is made taxable in the hands of the resident parent with the lower taxable income.

\section{Participation Income}

As well as the changes listed in the first section, the following changes are made:

\section{Participation Income}

The PI I set at $£ 3,902$ per year ( $£ 75$ per week). All adults (people not entitled to child benefit) are eligible and are assumed to meet any participation condition.

\section{Income tax changes}

The personal income tax allowance and age allowances are set to zero.

\section{Interaction with the tax-benefit system}

Existing incomes from non means-tested earnings replacements benefits (referred to as $\mathrm{T}$ ) are considered as contributing towards the Participation Income entitlement. 
These include contributory JSA and ESA, residual Incapacity Benefit, Industrial Injuries Benefit, basic State Pension, Bereavement Allowance and Maternity Allowance. For eligible individuals with incomes T $>$ PI Participation Income is set to zero. For eligible individuals with incomes $\mathrm{T}<=$ PI Participation Income is equal to the difference of the two (i.e. PI - T).

The PI is not itself taxed. Child Benefit is not taxed in the PI package.

Individuals pay tax on $T_{n}$ (where $T_{n}$ is $T$ net of industrial injuries benefit and maternity allowance). However, in the tax treatment $T_{n}$ is reduced by the maximum between their entitlement to PI or the basic State Pension in case they receive the latter.

PI enters the income-tests for the benefits Child Tax Credit, Working Tax Credit, Housing Benefit, Council Tax Benefit, Pension Credit, Income Support and income tested JSA and ESA.

\section{The Minimum Wage}

Raising the minimum wage is considered as a stand-along reform and in combination with the SI package and PI package in turn.

The minimum wage is increased from $£ 6.31$ to $£ 7.85$ per hour for those aged 21 and over with positive employment income not living in London and to $£ 9.15$ per hour for those living in London. For those aged 18 to 20, the minimum wage is increased from $£ 5.03$ to $£ 6.26$ per hour outside London and to $£ 7.29$ in London. Finally, for those aged 16 and 17 the minimum wage is increased from $£ 3.72$ to $£ 4.63$ outside London and to $£ 5.39$ in London.

\section{References}

Adam, S., Browne, J.: Redistribution, Work Incentives and Thirty Years of UK Tax and Benefit Reform. IFS Working Paper W13/26. Institute for Fiscal Studies, London (2010)

Adam, S., Browne, J.: Do the UK Government's Welfare Reforms Make Work Pay? IFS Working Paper W13/26. Institute for Fiscal Studies, London (2013)

Araar, A., Duclos, J.Y.: DASP: Distributive Analysis Stata Package. PEP, World Bank, UNDP and Université Laval (2007)

Atkinson, A.B.: Incomes and the Welfare State: Essays on Britain and Europe. Cambridge University Press, Cambridge (1995)

Atkinson, A.B.: Inequality: What Can Be Done? Harvard University Press, Cambridge (2015)

Atkinson, A.B., Bourguignon, F., O’Donoghue, C., Sutherland, H., Utili, F.: Microsimulation of social policy in the European Union: case study of a European minimum pension. Economica 69, 229-243 (2002)

Bargain, O., Immervoll, H., Viitamäki, H.: No claim, no pain. Measuring the non-take-up of social assistance using register data. J. Econ. Inequal. 10, 375-395 (2012)

Bennett, F., Sutherland, H.: The Importance of Independent Income: Understanding the Role of Nonmeans-tested Earnings Replacement Benefits. ISER Working Paper 2011-09. ISER, University of Essex, Colchester (2011)

Bourguignon, F., Spadaro, A.: Microsimulation as a tool for evaluating redistribution policies. J. Econ. Inequal. 4(1), 77-106 (2006)

Brewer, M., De Agostini, P.: The National Minimum Wage and its interaction with the tax and benefit system: a focus on Universal Credit. EUROMOD Working Paper Series EM2/15. ISER, University of Essex, Colchester (2015)

Browne, J.: The Impact of Proposed Tax, Benefit and Minimum Wage Reforms on Household Incomes and Work Incentives, Report R111. Institute for Fiscal Studies, London (2015)

Butcher, T., Dickens, R., Manning, A.: Minimum Wages and Wage Inequality: Some Theory and an Application to the UK. Centre for Economic Performance Discussion Paper. London School of Economics and Political Science, London (2012) 
D’Arcy, C., Corlett, A., Gardiner, L.: Higher Ground: Who Gains from the National Living Wage? Resolution Foundation, London (2015a)

D’Arcy, C., Kelly, G.: Analysing the National Living Wage Impact and Implications for Britain's Low Pay Challenge. Resolution Foundation, London (2015b)

De Agostini, P., Sutherland, H.: EUROMOD Country Report: United Kingdom 2009-2013. ISER, University of Essex, Colchester (2014)

Department for Work and Pensions: Income Related Benefits Estimates of Take-Up in 2008/2009. DWP, London (2010)

Dickens, R., Manning, A.: Has the national minimum wage reduced UK wage inequality? J. R. Stat. Soc. A 167, 613-626 (2004a)

Dickens, R., Manning, A.: Spikes and spillovers: the impact of the national minimum wage on the wage distribution in a low wage sector. Econ. J. 114, C95-101 (2004b)

Eurofound: Access to Social Benefits: Reducing Non-take-up. Publications Office of the European Union, Luxembourg (2015)

Figari, F., Paulus, A., Sutherland, H.: Microsimulation and policy analysis. In: Atkinson, A.B., Bourguignon, F. (eds.) Handbook of Income Distribution, vol. 2B, pp. 2141-2221. Elsevier (2015)

Gugushvili, D., Hirsch, D.: Means Testing Versus Universalism: What Strategies Best Address Poverty? A Review Contributing to Joseph Rowntree Foundation's Development of an Anti-poverty Strategy. Centre for Research in Social Policy, Loughborough University (2014)

Hancock, R., Pudney, S., Barker, G., Hernandez, M., Sutherland, H.: The take-up of multiple means-tested benefits by British pensioners: evidence from the Family Resources Survey. Fisc. Stud. 25(3), 279-303 (2004)

HM Revenue and Customs: Child Tax Credit and Working Tax Credit Take-up Rates 2008-09. HMRC, London (2010)

Hernandez, M., Pudney, S., Hancock, R.: The welfare cost of means-testing: pensioner participation in income support. J. Appl. Econom. 22, 581-598 (2007)

Hood, A., Oakley, L.: The Social Security System: Long-Term Trends and Recent Changes. IFS Briefing Note BN156. Institute for Fiscal Studies, London (2014)

Levy, H., Matsaganis, M., Sutherland, H.: Towards a European Union child basic income? Within and between country effects. Int. J. Microsimul. 6(1), 63-85 (2013)

Low Pay Commission: National Minimum Wage: Low Pay Commission report 2015, cm 9017, London (2015)

Martinelli, L.: The Fiscal and Distributional Implications of Alternative Universal Basic Income Schemes in the UK. IPR Working Paper, Institute for Policy Research, University of Bath (2017)

Marx, I., Nolan, B.: In-work poverty. In: Cantillon, B., Vandenbroucke, F. (eds.) Reconciling Work and Poverty Reduction: How Successful are European Welfare States? Oxford University Press, Oxford (2014)

Marx, I., Nolan, B.: The welfare state and antipoverty policy in rich countries. In: Atkinson, A.B., Bourguignon, F. (eds.) Handbook of Income Distribution. North-Holland, Amsterdam (2015)

OECD: In It Together: Why Less Inequality Benefits All. OECD, Paris (2015a)

OECD: All on Board: Making Inclusive Growth Happen. OECD, Paris (2015b)

Parker, H.: Instead of the Dole: An Enquiry into Integration of the Tax and Benefit Systems. Routledge, London (1989)

Piachaud, D.: Citizen's Income: Rights and Wrongs. CASEpaper 200 CASE, London School of Economics and Political Science (2016)

Reed, H., Lansley, S.: Universal Basic Income: An Idea Whose Time has Come? Compass, London (2016)

Skinner, C., Stuttard, N., Beissel-Durrant, G., Jenkins, J.: The measurement of low pay in the UK Labour Force Survey. Oxf. Bull. Econ. Stat. 64, 653-676 (2002)

Standing, G.: The Precariat: A New Dangerous Class. Bloomsbury, London (2014)

Stewart, M.: Wage Inequality, Minimum Wage Effects and Spillovers, Economic Research Papers. University of Warwick, Warwick (2011)

Stiglitz, J.E.: The Price of Inequality. W. W. Norton \& Company, New York (2012)

Sutherland, H., Figari, F.: EUROMOD: the European Union tax-benefit microsimulation model. Int. J. Microsimul. 6(1), 4-26 (2013)

Torry, M.: Money for Everyone: Why We Need a Citizen's Income. Policy Press, Bristol (2013)

Torry, M.: The Feasibility of Citizen's Income. Palgrave Macmillan, New York (2016)

Van Parijs, P.: Real Freedom for All. Clarendon Press, Oxford (1995)

Van Parijs, P., Vanderborght, Y.: Basic Income: A Radical Proposal for a Free Society and a Sane Economy. Harvard University Press, Cambridge (2017)

Vaughan-Whitehead, D. (ed.): The Minimum Wage Revisited in the enlarged EU. International Labour Office, Geneva (2009) 